\title{
12
}

\section{Enter the Ceramic Matrix: Identifying the Nature of the Early Austronesian Settlement in the Cagayan Valley, Philippines}

\author{
Helen Heath, Glenn R. Summerhayes and Hsiao-chun Hung
}

This paper addresses a major gap in our knowledge: the nature of Austronesian societies associated with the spread of the Neolithic through Island Southeast Asia. It addresses this gap by presenting a pilot study on the changing nature of settlement through pottery production from the Neolithic to the Iron Age. A physico-chemical analysis of pottery from the site of Nagsabaran located in Lal-lo, Cagayan Valley, Northern Luzon, Philippines, was undertaken and the data are used to assess models of mobility and sedentism in order to understand the nature of these early Austronesian communities. The research carried out through the physico-chemical analysis suggests more mobile populations during the Neolithic in the Cagayan Valley changing through time to a more sedentary society in the Iron Age.

\section{Introduction}

The dispersal and spread of Austronesian-language speakers from Taiwan into the Philippines and onwards through Island Southeast Asia (ISEA) and the Pacific has received much attention over the last decade (see Bellwood 2013 and 2015 for updates). One of the archaeological signatures of this spread in ISEA is seen as red-slipped pottery, which has been identified in numerous excavations throughout the region (Bellwood 2015: 286-287). Yet, in modelling this spread we have little data on the nature of Austronesian society. Bellwood (2011: S363) argues that Austronesian dispersal out of Taiwan was fuelled by population growth 'and a need for new cultivation land' (Bellwood 2015: 290). He sees the spread in the context of: 1. pressure from increasing populations of southern China and Taiwan; 2. advanced technology (he refers to boat construction and carpentry); 3. a dependence on agriculture and animal domestication; and 4. a 'portable food production repertoire that allowed long distance dispersal to take place'. Bellwood (2015: 286) also notes that the pretexts for this spread are now 'well documented' with the 'documentation of a six fold or greater increase in site numbers during the course of the third millennium BCE in eastern Taiwan' (Hung 2005: 126). From Taiwan, populations of Malayo-Polynesian speakers moved into the Philippines where sites in the Batanes Islands and the Cagayan Valley in northern Luzon have produced substantial assemblages of red-slipped pottery, plain-ware and incised and stamped pottery and other material culture dating to around 
4000-3500 BP (Bellwood 2015: 286). From the Philippines one branch of the diaspora appears to have involved a sea crossing of $c a .2,300 \mathrm{~km}$ to the Marianas (Hung et al. 2011; Carson et al. 2013), whilst other human populations dispersed south and southwest across ISEA, with both strands eventually ending up in the Bismarck Archipelago before proceeding on to Near and Far Oceania. The absence of substantial linguistic differentiation suggests the diaspora from the Philippines south and east into ISEA and Oceania was fairly rapid. To emphasise the expeditious maritime movements of the Malayo-Polynesian-speaking peoples, Jared Diamond (1988: 307-308) coined the term 'express train'. Archaeologists in the Pacific have long acknowledged that this expansion was never simple, but rather a complex interplay of the three 'Is': Innovation, Integration and Introduction (Green 1991, 2000, 2003).

The defining of early Malayo-Polynesian settlement patterning has been aided in the western Pacific by the identification of more than 220 Lapita sites (see Anderson et al. 2001; Summerhayes 2007; Bedford and Sand 2007), which suggest a change from high mobility during early Lapita colonisation to subsequent sedentism and permanent villages. This change has been successfully modelled based on physico-chemical analysis of present-day pottery in Melanesia and its production and distribution (Summerhayes 2000a, 2003, 2004). On the basis of the selection of both clays and mineral fillers, and comparing them to pottery form and stylistic variation/similarities, a series of pottery scenarios was defined differentiating between specialist production, household production, and mobile community production. These scenarios were used as heuristic frameworks for comparison with the production of archaeological pottery assemblages (see Summerhayes 2000a for further details).

In contrast to the intensive studies on Lapita pottery, there has been little similar research on pottery from archaeological sites in ISEA and the information ceramic analysis might provide us with regard to settlement patterning and mobility in this region. To redress this imbalance a physico-chemical analysis was undertaken on pottery from the key settlement site of Nagsabaran, located in northern Luzon, Philippines. Nagsabaran possesses a material culture repertoire with strong similarities to the Taiwan Neolithic (Bellwood and Dizon 2005), and is thus considered to represent one of the earliest settlement sites inhabited by colonists entering ISEA from Taiwan. It is a well-dated archaeological site with deep stratigraphy and chronological sequence that encompasses both the regional Neolithic (4000-2500 BP) and Iron Age (2500-1500 BP). Most importantly, it produced a substantial assemblage of decorated and plain pottery that has the potential to provide interesting new information on the nature of human habitation in some of the earliest Malayo-Polynesian settlements outside of Taiwan.

The project aimed to answer two questions: 1. What is the nature of pottery production in the Nagsabaran site; and 2. Is there a change through time from pottery production in the Neolithic to the Iron Age? These questions were addressed through a physico-chemical analysis of the ceramic assemblage within the two distinct phases of occupation at the site. The outcomes of the chemical analyses were used to develop models of mobility similar to those outlined by Summerhayes (2000a, 2000b) for the spread of Lapita in the western Pacific. 


\section{Nagsabaran - Northern Luzon}

The Nagsabaran shell mound is located in the Lal-lo region of the Cagayan Valley, northeast Luzon, about $20 \mathrm{~km}$ inland on the south bank of Zabaran Creek/Nagsabaran Creek, to the west of the Cagayan River (Figure 12.1; Carson et al. 2013: 21).

Originally called the Alaguia shell midden in the early 1990s, the site was renamed Nagsabaran in 1996 by a Filipino-Taiwanese team who undertook initial excavations at the site a few years later, in 2000 to 2001 . The excavation of eight test pits (Pits 1-8) resulted in the identification of two distinctive depositional sequences: an upper 'Metal Age' shell mound 1-3 m thick, overlying alluvial silts containing 'Neolithic' material culture between 1-2 m in depth. Sandwiched between these cultural deposits was a sedimentary horizon devoid of archaeological remains, suggesting a hiatus between the 'earlier' and 'later' phases of activity. This hiatus is especially clear within the southeast area of the site (Hung 2008). A similar 'hiatus' has been recorded on other sites in the Lal-Lo region, and Tanaka (2002) has proposed that this widespread abandonment might have been a result of flooding.

Further excavations in 2004 of Pits 9 and 10 in southeast area of Nagsabaran by archaeologists from The Australian National University and the National Museum of the Philippines confirmed the stratigraphic sequence recorded in 2000-2001, and the substantial differences between the material culture identified in the shell mound and that recorded in the underlying silt deposits (Hung 2008; Figure 12.2). Hung (2008) noted that the material culture was discontinuous between the upper shell mound deposits (with the hiatus between Spits 8 and 11) that contained black, brown or red pottery (some slipped), glass beads, glass bracelets, iron tools, fired clay pendants, jar burials with human skulls and headless extended burials, and beneath the 'hiatus' where three layers of silt sediments produced red slipped pottery (occasionally with punctate stamping and lime infill), course buff or beige pottery, spindle whorls, fired clay penannular earrings and pendants, stone flakes and adzes, and bone of pig and deer.

In 2009, another four trenches (Pits 11-14) were excavated towards the middle of the shell mound (Pit 14), close to the southeast periphery of the site near former Pits 9 and 10 (Pits 11 and 12), and yet further to the southeast (Pit 13). Although the previously documented 'threelayer' sequence of deposits was identified, much greater stratigraphic resolution was determined, especially within the shell mound. The shell mound could be differentiated into large dumps of complete or almost complete shells devoid of material culture separated by thin humic layers containing substantial amounts of pottery and bone. Numerous postholes were recorded truncating pre-existing shell mound layers (and often into the underlying silts) from the humic (occupation) layers. Some postholes measured more than $0.8 \mathrm{~m}$ in diameter and over $1 \mathrm{~m}$ in depth and contained pottery and stone used as 'post-packing' to stablise the post in the ground. These posts were clearly designed to support substantial above ground structures. Amano et al. (2013) interpreted the sequential build-ups of shell mound interspersed with habitation and construction on the mound as deliberate attempts to increase the height of the mound, and hence structures above the surrounding environment, perhaps to avoid flooding. This interpretation however is debatable.

Below the shell mound was a dark humic layer full of pottery and bone that marked the initial phases of re-occupation of the site, prior to the development of the shell mound. This layer was deposited directly on top of $0.2-0.3 \mathrm{~m}$ of sterile 'hiatus' deposits. Beneath this was the silty clay sediments containing high concentrations of red-slipped pottery and other material culture associated with the regional Neolithic. Some excavated postholes were assigned to this phase of activity. 


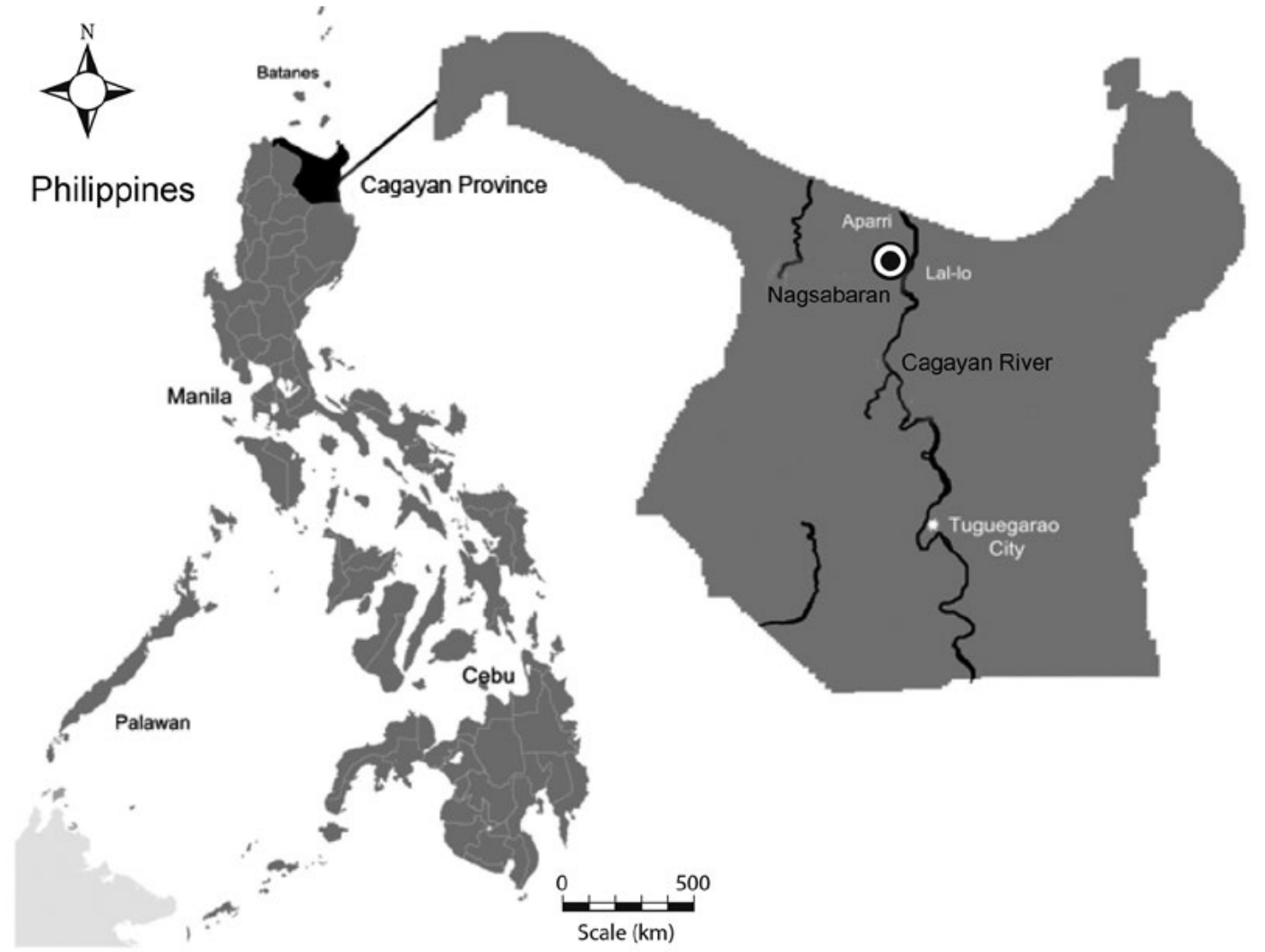

Figure 12.1 The location of Nagsabaran on the east side of the Cagayan River close to Lal-lo in northern Luzon, Philippines.

Source: After Amano et al. 2013.

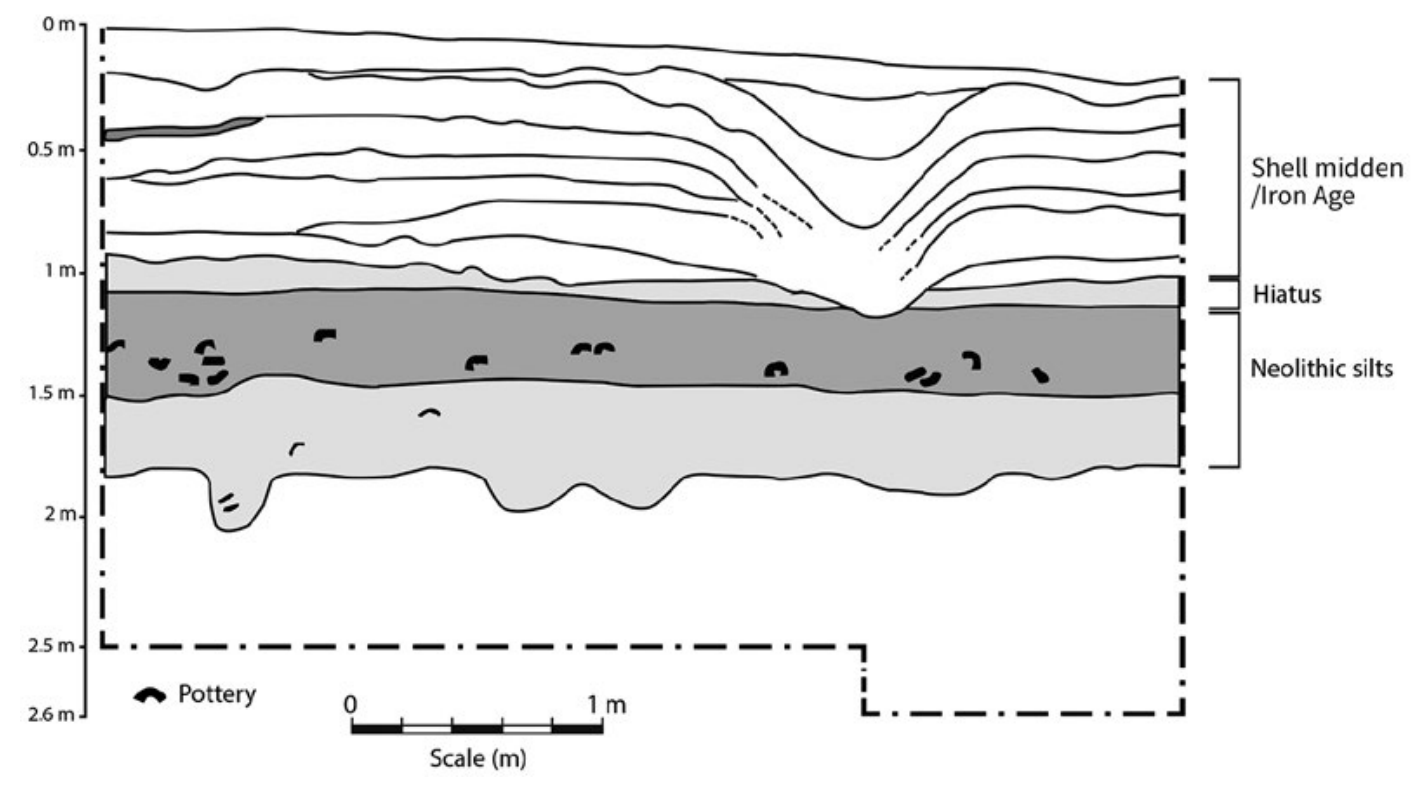

Figure 12.2 Stratigraphy of Test Pit 9 from Nagsabaran.

Source: Redrawn from Hung 2008. 
The previous 31 radiocarbon dates (on charcoal, shell and bone) suggested that the occupation in the southeast area of the site was initially at 4000 through $2600 \mathrm{BP}$, and again at 2100 through $1500 \mathrm{BP}$ (Hung 2008). In comparison to the gap or hiatus at 2600 through $2100 \mathrm{BP}$ in the southeast portion of the site, more recent work has identified burial features dated to within this 'gap' in the central area of the site.

\section{Studying human mobility through using physico-chemical analysis of pottery}

Chemical analysis combined with other research on pottery, including morphology and design, can demonstrate potential interactions between communities. For example, if clays sourced for pottery production are local but there are design similarities across broad regions, then social, cultural and/or ideological coalesence could be invoked to account for the geographic distribution of motifs, rather than simple pottery exchange (Summerhayes 2000a: 30). Analyses can, however, go beyond identifying whether interaction occurred, and can potentially inform us about the nature of settlement patterning and mobility as well. For instance, by comparing the clays and fillers used in the production of pottery, Summerhayes (2000a, 2000b, 2003) was able to identify changing resource use and production techniques and relate these to Lapita mobility/settlement patterns within the Bismarck Archipelago. The results suggest that though Early Lapita pottery was mostly locally produced, the potters used diverse combinations of clays and tempers/fillers from various different geographic locations along river systems and beaches to produce the same vessel forms with identical decoration (Figure 12.3). In later periods, Lapita production continued to be locally based but manufacturing techniques became more conservative and standardised with only one clay source and a limited range of temper/fillers utilised in the construction of all pottery (Figure 12.4). The change in source material acquisition from Early to Late Lapita in the Bismarcks was interpreted as reflecting a change in settlement patterns, with the early production pattern resulting from higher mobility associated with the initial colonisation period and the later pattern reflecting more sedentary communities.

Neither the Early nor Late Lapita production and distribution patterns corresponded to modern specialist pottery production for exchange seen in the ethnographic past from a number of areas in Papua New Guinea. These differences are represented graphically by comparing Figures 12.3 and 12.4 with the representation of specialist production in Figure 12.5.

In contrast to Lapita studies, almost no physico-chemical studies of pottery have been attempted to explain patterns of human mobility in ISEA. However, it should be noted that a previous physico-chemical analysis on pottery from the northern Philippines was undertaken earlier by Swete Kelly (2008). Unlike the study proposed here, Swete Kelly aimed to assess human social interaction associated with Austronesian dispersals. She analysed pottery samples from two east coast Taiwan sites, three from the Batanes, two from the Cagayan Valley, and one from east Luzon (Dimolit). Yet, the analysis was to determine similarities rather than specific production issues. Thus the nature of early settlement is unknown in the valley, even though links can be drawn between sites through pottery types, decoration and petrographic analysis (Aoyagi et al. 1986; Tanaka and Orogo 2000; Ogawa 2002; Tanaka 2002; Mijares 2005; Hung 2005, 2008). 


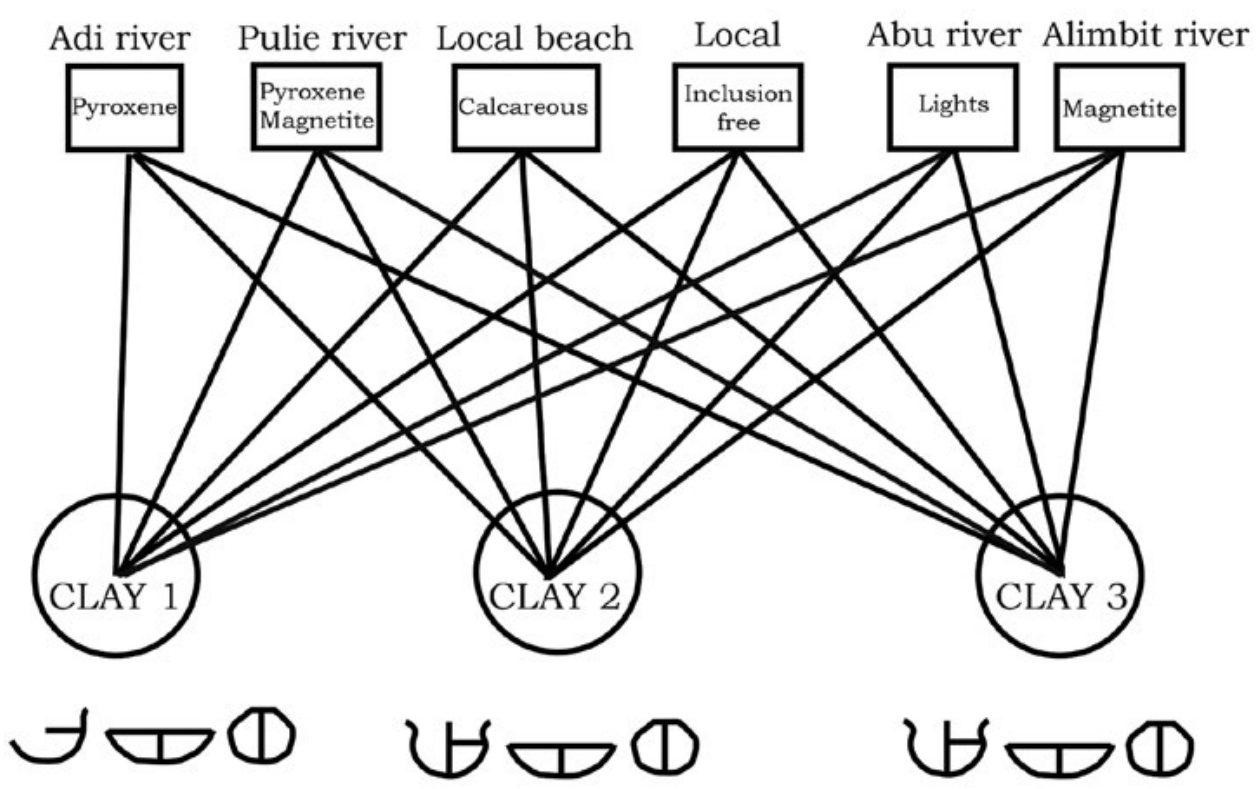

Figure 12.3 Pottery production indicating mobile settlement - selection of fabrics in the Early Lapita Arawe assemblages.

Source: G.R. Summerhayes.

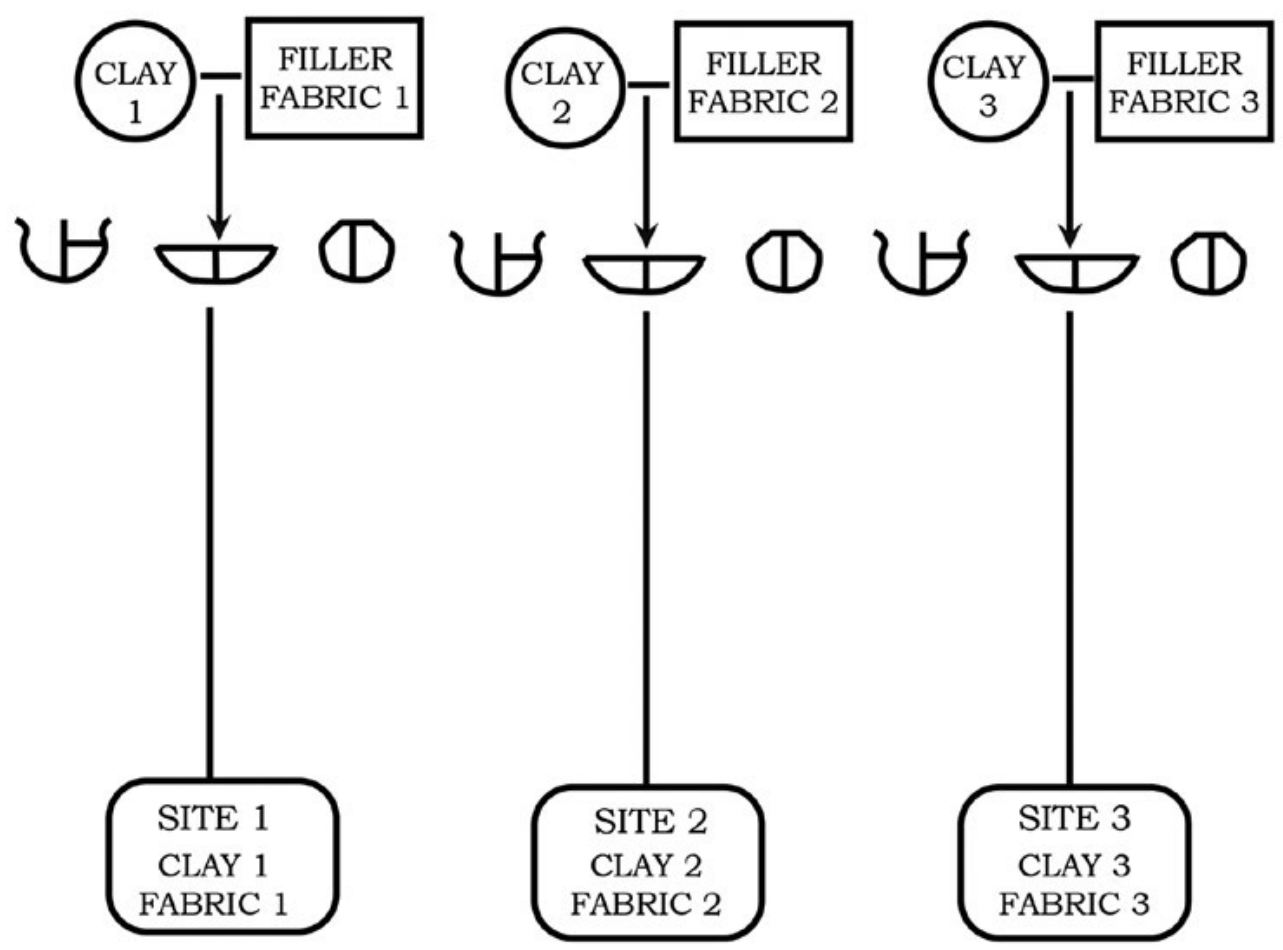

Figure 12.4 Selection of fabrics within Later Lapita assemblages: Sedentary signature. Source: G.R. Summerhayes. 


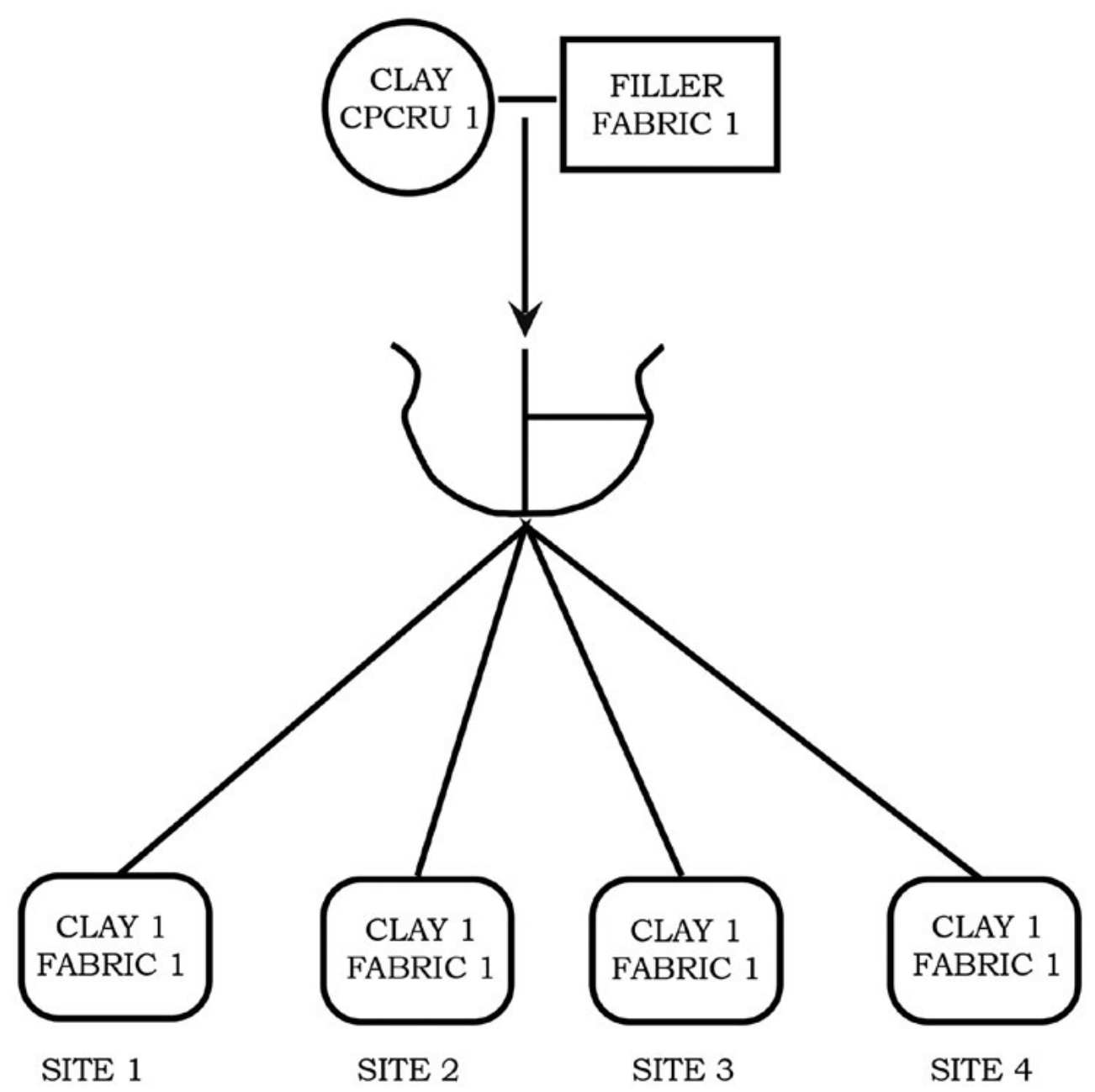

Figure 12.5 Selection of fabrics expected from specialist general production.

Source: G.R. Summerhayes.

There has been much research carried out on pottery style and decoration from Northern Luzon to the point where there is now a vast collection of recorded types of pottery (Tanaka 2002; Ogawa 2002; Hung 2008). Linking this with a physico-chemical analysis would add to an understanding of the region's past. There is much potential for a chemical analysis in the Cagayan Valley to help us understand the nature of interaction between communities, the distinction between distant and local clay sourcing as well as trade and exchange during the period.

\section{Sample selection - Nagsabaran}

For the purposes of this study, a sample of 47 sherds from throughout the stratigraphic sequence of Pits 9 and 10 (excavated in 2004) in the southeast area of Nagsabaran was selected by Hung for physico-chemical analysis (Table 12.1). Samples taken from Spits 10-18 in both pits were recovered from the lower silts and correspond to the earlier (Neolithic) phase of occupation at the site. Those from Spits 1-9 were retrieved from the sequence of shell mound deposits and all date to the Iron Age. As part of the preliminary analysis, the contextual information for each sherd was catalogued and each fragment's morphology, shape, colour and thickness were recorded. This information was useful in identifying whether form and/or function potentially played a role in the decision-making process with regard to raw material choice and manufacturing techniques. 
Table 12.1 Pottery samples selected for analysis.

\begin{tabular}{|l|l|}
\hline Spit & No. sherds \\
\hline Iron Age 2500-1500 BP \\
\hline 1 a & 1 \\
\hline 1 b & 1 \\
\hline 4 & 4 \\
\hline 5 & 6 \\
\hline 6 & 2 \\
\hline 7 & 4 \\
\hline 8 & 2 \\
\hline 9 & 4 \\
\hline Neolithic $4000-3000$ BP \\
\hline 11 & 4 \\
\hline 12 & 3 \\
\hline 13 & 9 \\
\hline 15 & 5 \\
\hline 17 & 1 \\
\hline 18 & 1 \\
\hline
\end{tabular}

Source: Authors.

\section{The Scanning Electron Microscope}

This study used the Zeiss Field Emission Gun Scanning Electron Microscope (FEGSEM) to chemically characterise the raw materials used in pottery production at Nagsabaran. As the samples for FEGSEM analysis for this study were required to be in briquette form, this technique could then distinguish between and provide separate chemical analysis of the ceramic matrix and mineral inclusions, something that is not possible with techniques using crushed samples (see Summerhayes (1997, 2000a, 2000b, 2007) for more detail). The FEGSEM is also known for its remarkably high resolution imaging that allows the analyst to accurately examine fine details (Gnauck et al. 2002; Froh 2004).

\section{Operating conditions}

The FEGSM, which is housed at the Otago Centre for Electron Microscopy (OCEM), uses an XMax20 silicon drift energy dispersive X-ray (EDX) detector and AZTEC acquisition and processing software from Oxford Instruments. An image of the sample is produced by the interactions between the electron beam and the sample. The surface is scanned line by line by a focused beam of electrons. Interactions are created by the primary electrons from the beam creating the emission of secondary electrons, backscattered electrons and X-rays, which are used to identify the topography of the sample surface and are collected by a detector to be displayed on a computer. The images obtained from scanning are referred to as electron micrographs with resolutions down to about a nanometre. By looking at this image a researcher can then target a desired mineral or clay with the electron beam. The beam travels into the sample and generates several signals. Through the interaction of these signals, the elemental makeup of that minerals or clay is collected and a picture of the studied surface is fed into a computer for further analysis (Froh 2004; see Zhou et al. 2006 for more on the fundamental workings of an SEM). 
Samples were made into polished briquettes and carbon coated. The elements, in oxide form, that were measured for clay analysis were as follows: magnesium, aluminium, silicon, phosphorus, potassium, calcium, titanium, and iron. Through the use of the electron microscope a statistically representative population of minerals within the temper and in the clay matrix can be identified.

\section{Clay matrices}

The data gathered for the clay matrices of the 47 samples was analysed through principal component analysis (PCA using Wrights MVARCH 1991), a statistical method commonly used in archaeological investigations (Summerhayes 2000a; Hogg 2007; Niziolek 2013). All samples were standardised using MVARCH. To evaluate the characterisation of production within the site, samples were grouped into Chemical Paste Compositional Reference Units (CPCRU). Defined by Bishop and Rands (1982; Bishop et al. 1982), CPCRUs are groupings of sherds based on their chemical similarity (see Summerhayes 2000a: Chapter 4).

\section{Inclusions}

Mineral inclusions within each sample were identified based on elemental makeup. The cataloguing of minerals was assembled within the AZTEC software so that statistically robust mineral composition data could be compiled and then analysed manually with known standard mineral compositions with the aid of the Deer et al. (1992) major text which outlines the elemental composition of all minerals.

\section{Results}

\section{Analysis of the clay matrix}

\section{Neolithic}

Five CPCRU (here called CPCRU 1 to 5) were identified in the Neolithic phase (Figure 12.6). CPCRU 1 contains the more samples $(\mathrm{N}=9)$ than any other CPCRU, with six identified in Spit 13, and one respectively from Spits 18, 15 and 12. The chronological spread of samples within this CPCRU (from Spits 12 to 18) suggests continual use of the same clay source region throughout much of the earlier phase of occupation at Nagsabaran. CPCRU 2 contains eight samples spread between Spits 11 to 15, and CPCRU 3 contains four samples from Spits 12 to 15. CPCRU 4 (Spit 17) and 5 (Spit 11) are outliers containing a single sample each. The available samples do not suggest any trend towards increasing or decreasing CPCRU variability over time during the Neolithic phase of occupation.

\section{Iron Age}

Of the three CPCRUs recorded for the Metal Age phase (Figure 12.7), CPCRU 1 contains 12 samples from Spits 1-8, CPCRU 2 possesses eight samples from between Spits 4 and 9 and CPCRU 3 consists of a single outlier from Spit 5. 


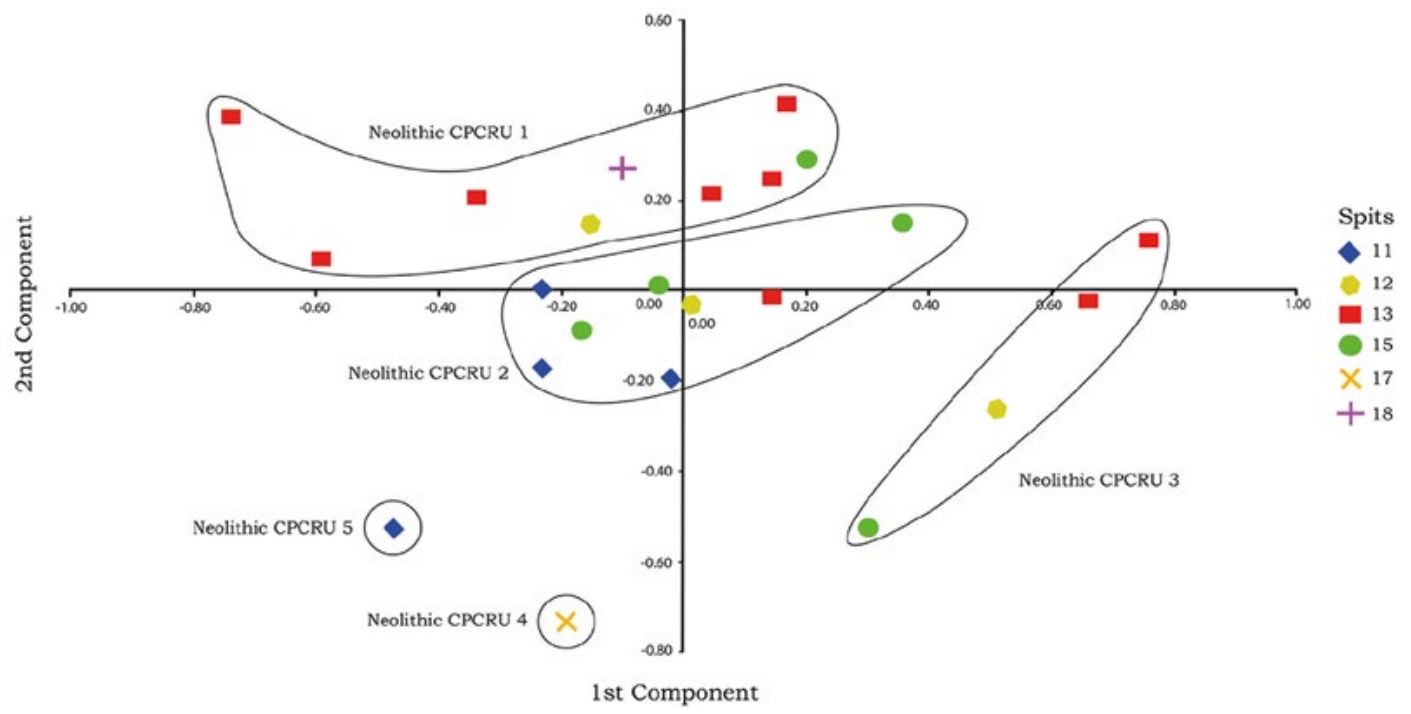

Figure 12.6 PCA plot of Neolithic showing CPCRUs.

Source: Authors.

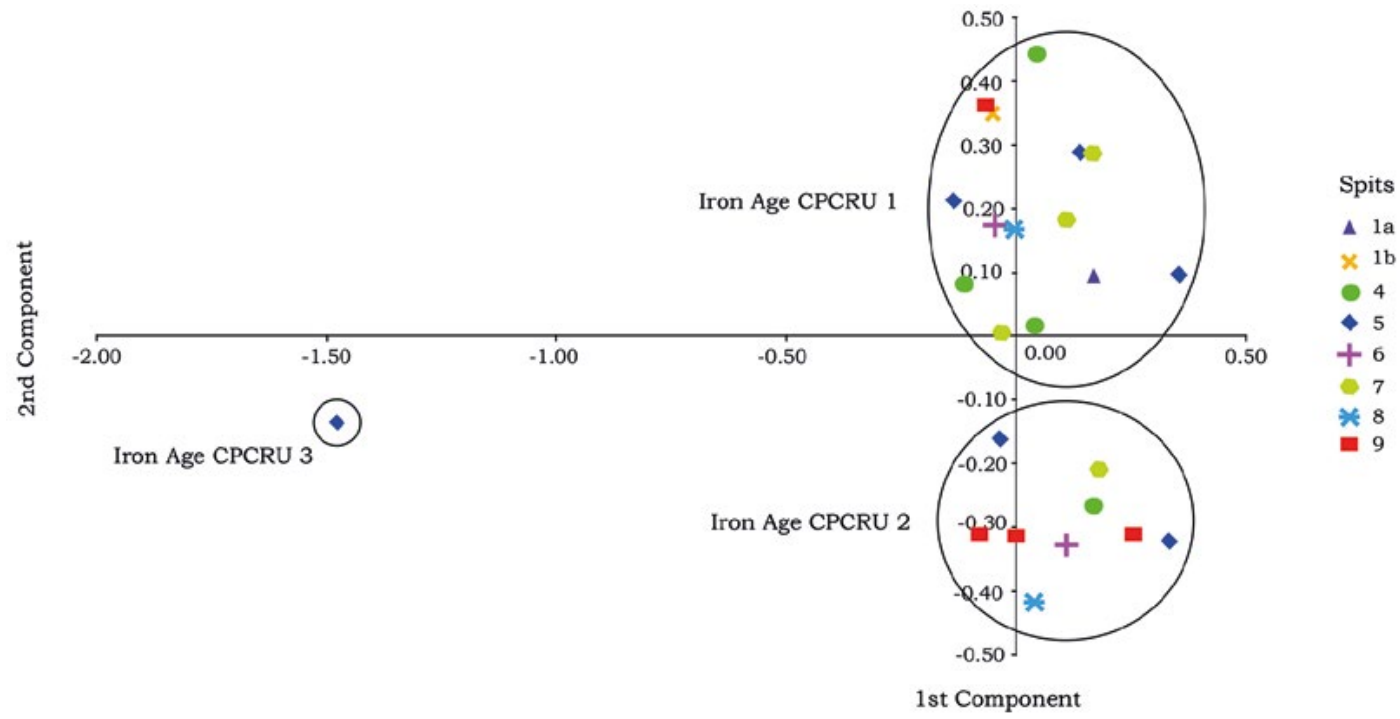

Figure 12.7 PCA plot of Iron Age showing CPCRUs.

Source: Authors.

\section{All layers}

With the exception of the two single Neolithic CPCRU samples (4 and 5), which fall within the range of the Iron Age specimens, and Iron Age sample 13 that appears to be a clear outlier, the Neolithic and Iron Age samples separate fairly neatly from each other with respect to clay matrices (Figures 12.8 and 12.9). 


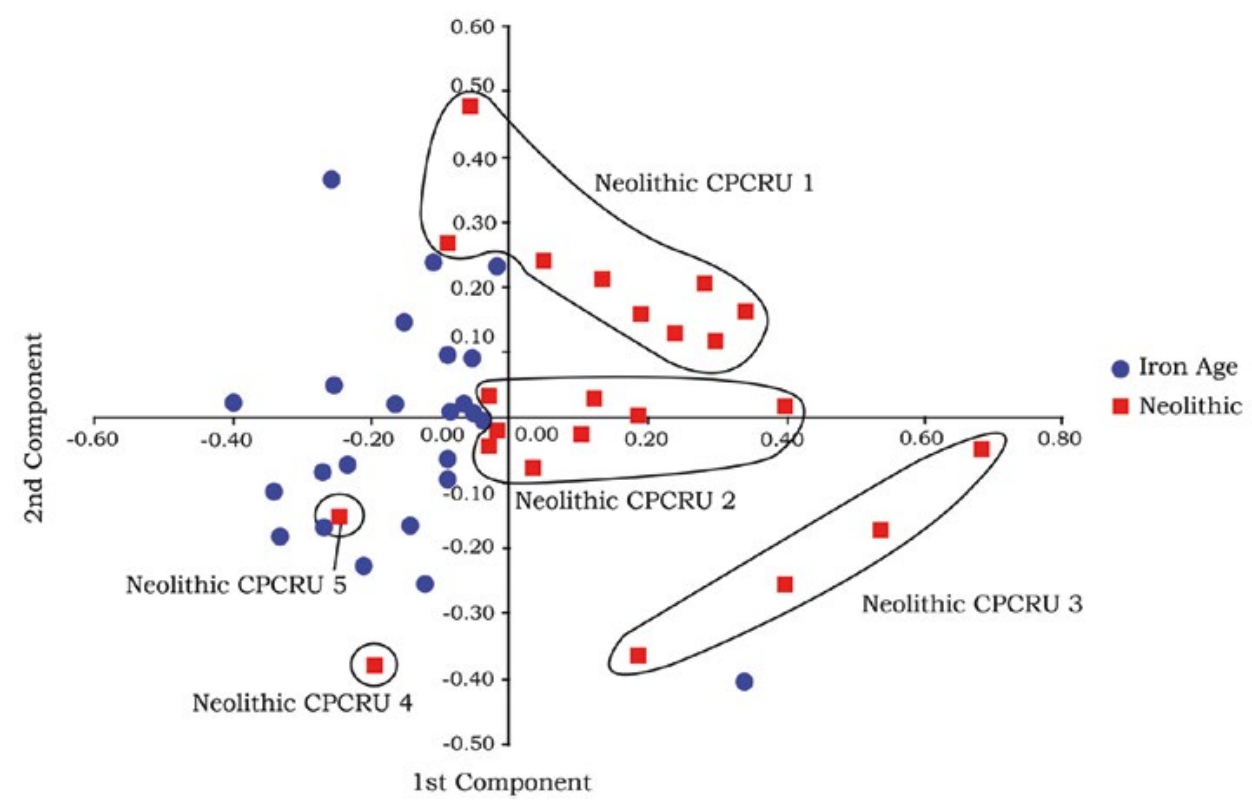

Figure 12.8 Comparison of Neolithic and Iron Age CPCRUs using components 1 and 2. Source: Authors.

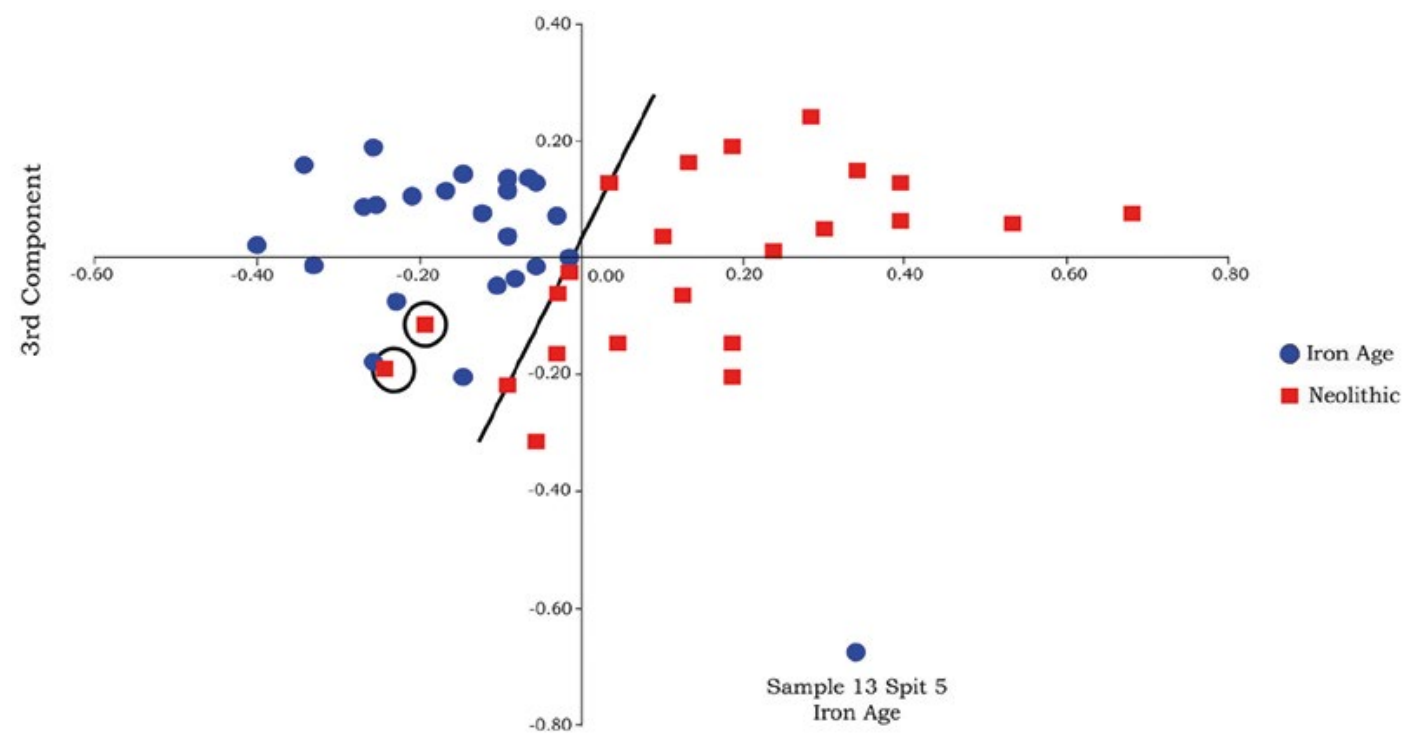

1st Component

Figure 12.9 Comparison of Neolithic and Iron Age CPCRUs using components 1 and 3.

Source: Authors.

\section{Mineral inclusions - fabrics}

Plagioclase feldspars and quartz were recorded in all Neolithic (Figure 12.10) and Iron Age (Figure 12.11) samples, albeit in varying quantities. Haematite and Ilmenite were present in the majority of the Neolithic and Iron Age specimens and amphiboles were absent from just five of the tested samples. Despite clear similarities in mineral inclusions there is also some notable sample variability that suggests mineral fillers were being collected from different geographic locales, but within a region with consistent underlying geology. For example, pyroxenes were identified in only 15 of 23 Neolithic specimens and eight of 23 Iron Age samples. Similarly epidote was 
found in only 15 Neolithic and six Iron Age samples. Alkaline feldspars were relatively rare being found in only two Neolithic and one Iron Age samples. Other rare components in Neolithic samples were zircon (one sample, 29) and copper (two samples, 38 and 47) (see Table 12.2).

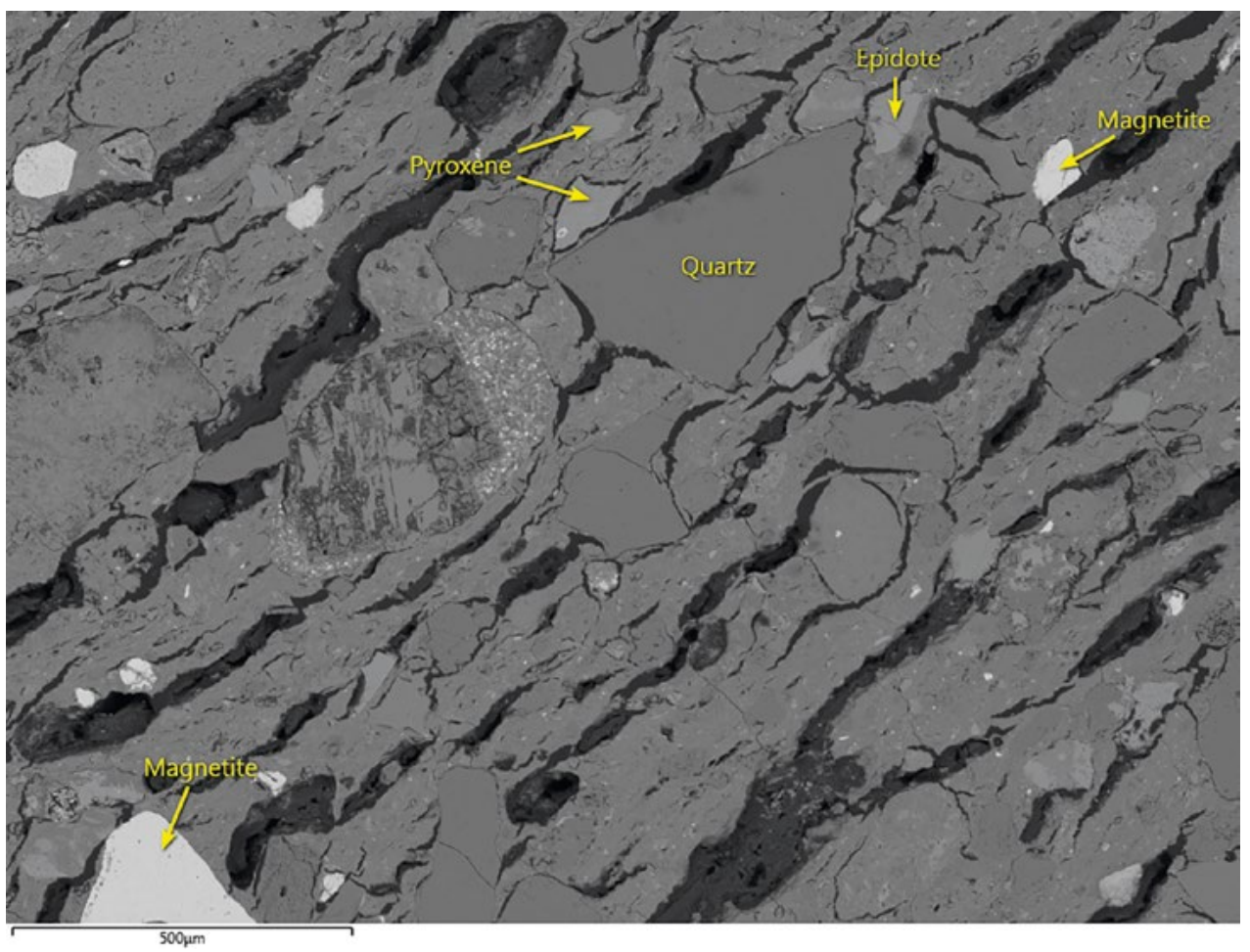

Figure 12.10 Image of pottery fabric - Neolithic at 160x magnification.

Source: Authors.

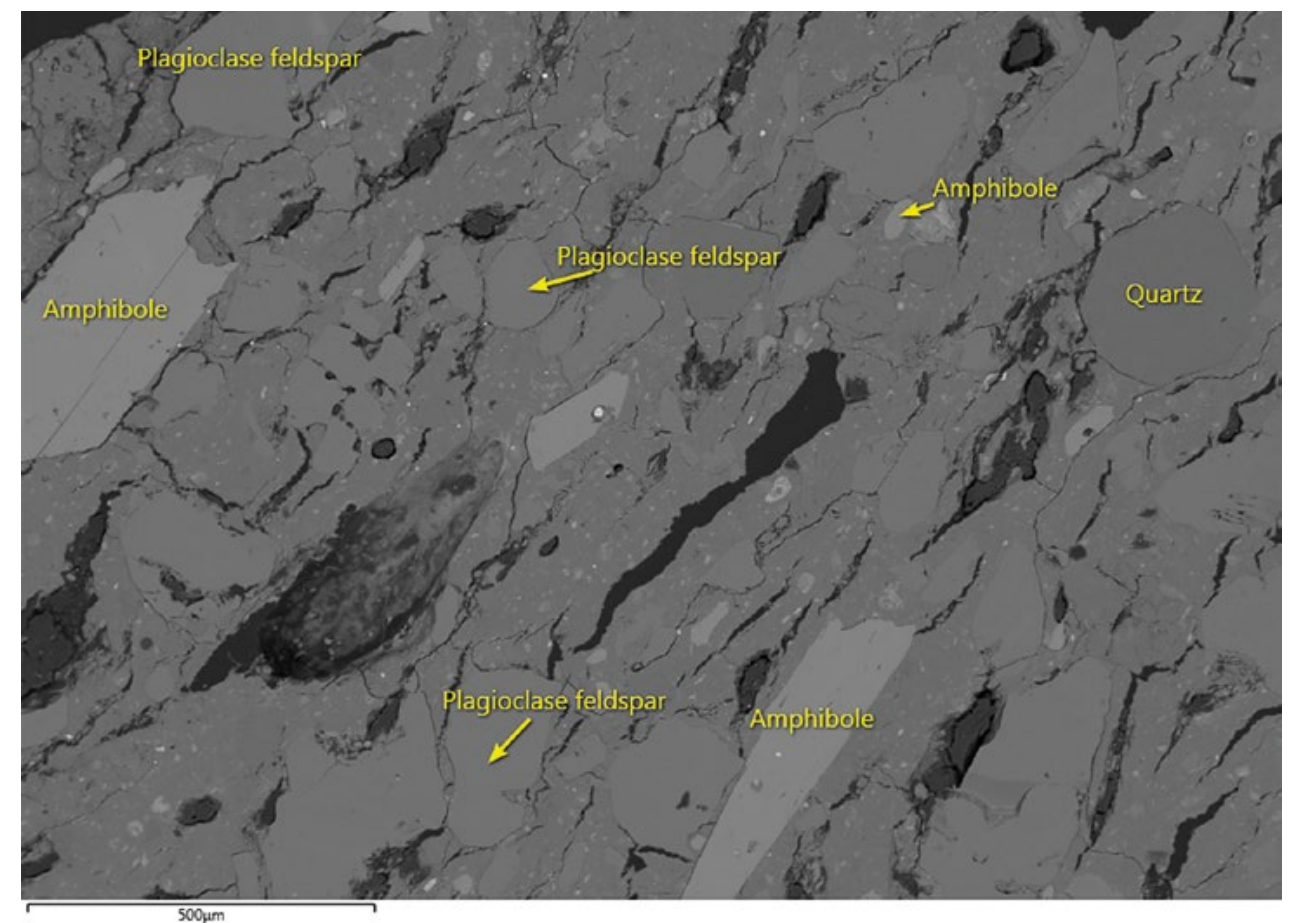

Figure 12.11 Image of pottery fabric - Iron Age at 160x magnification.

Source: Authors. 


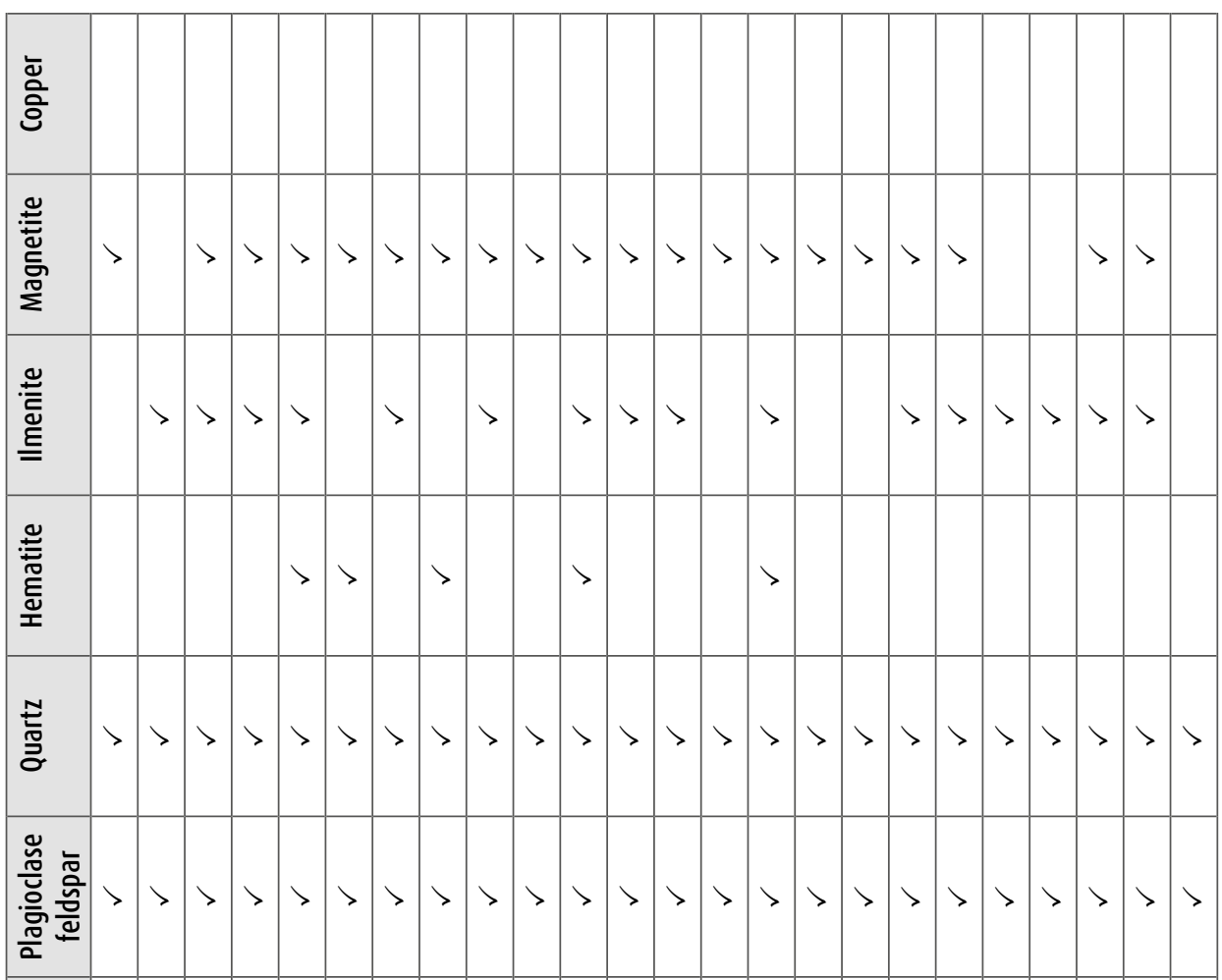

흔

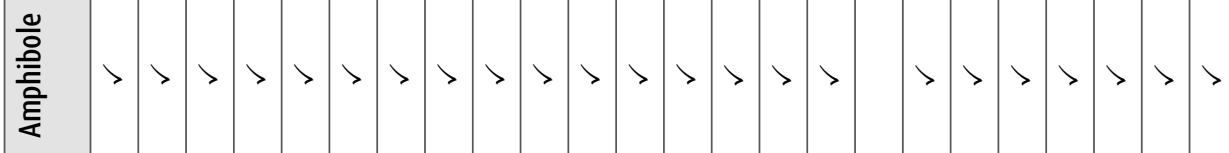

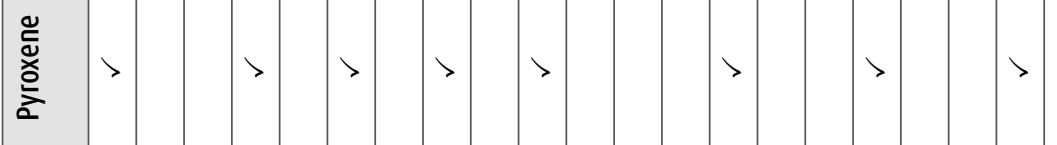

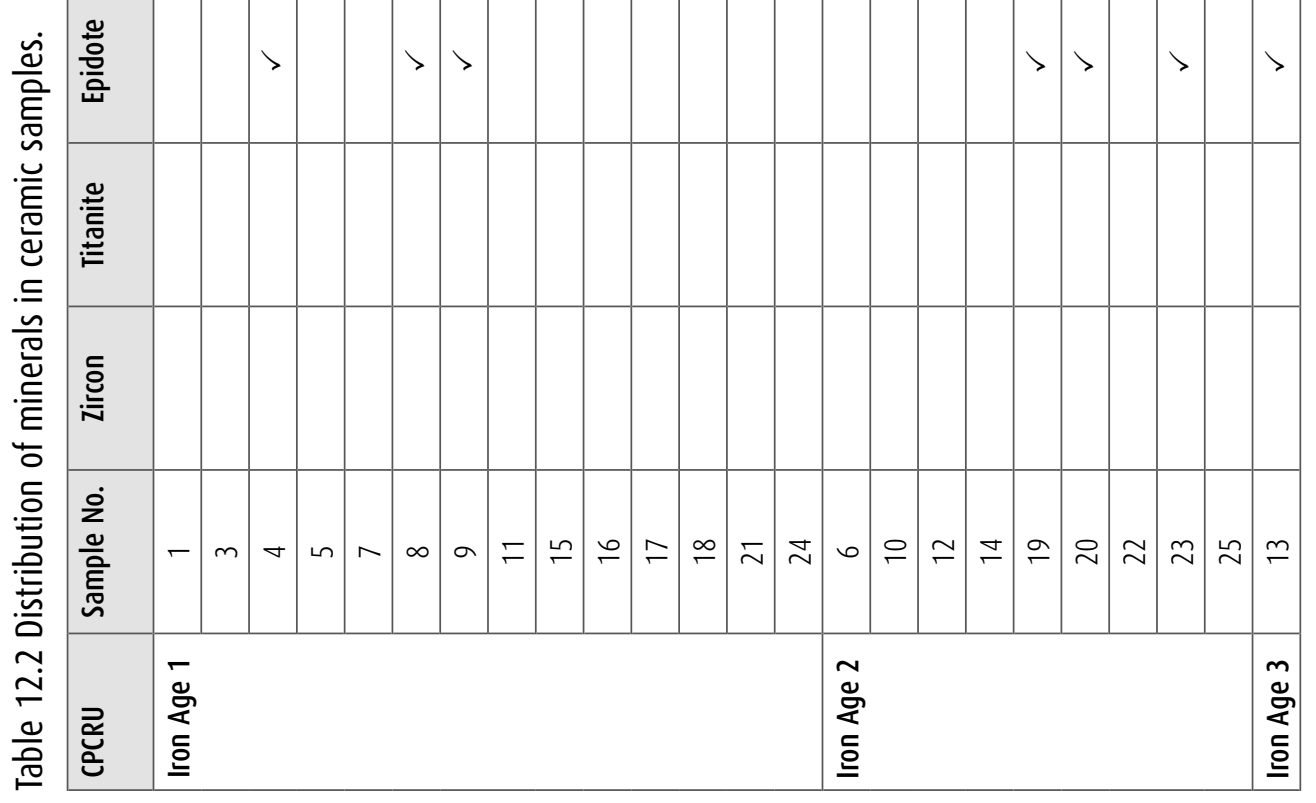




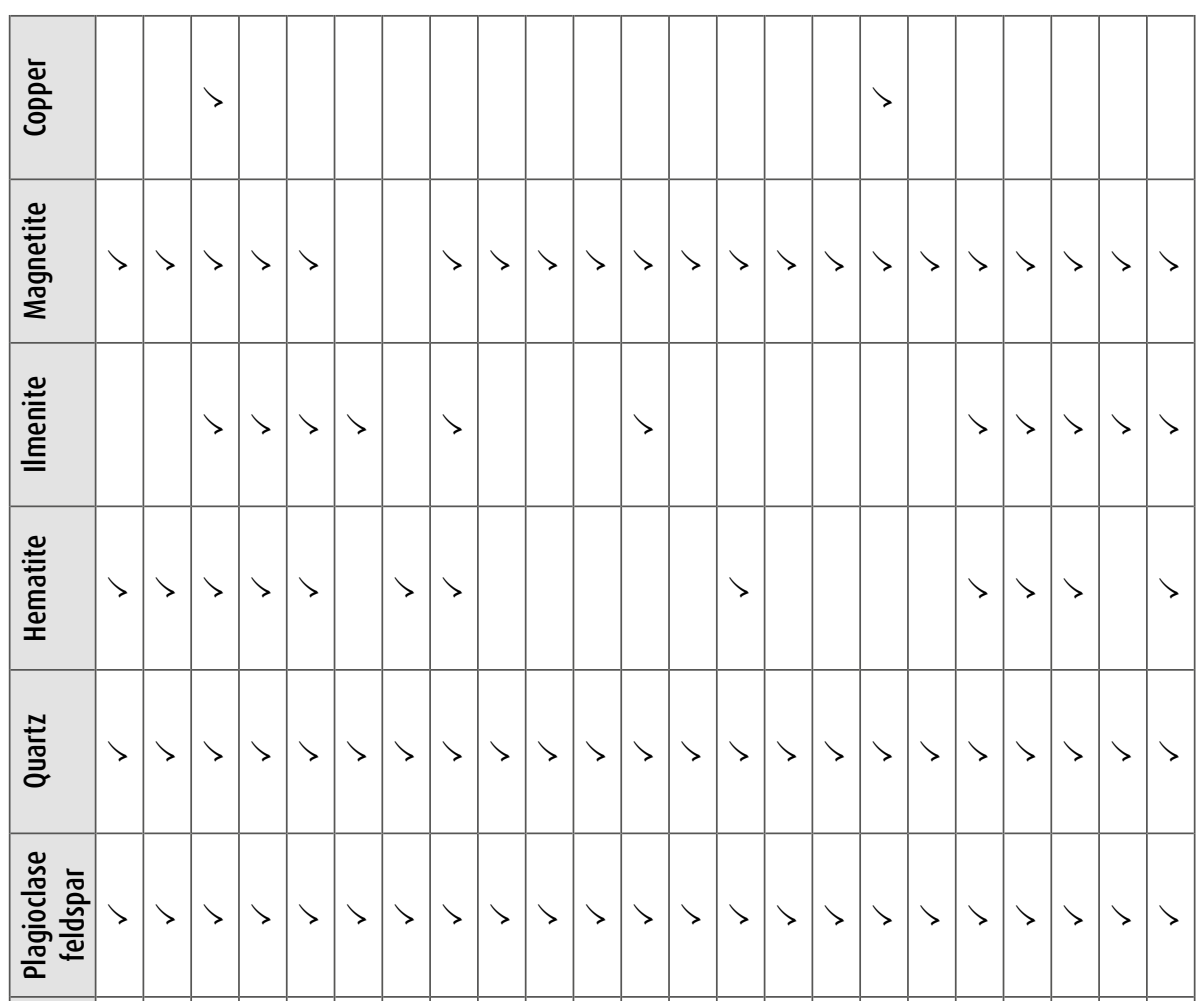

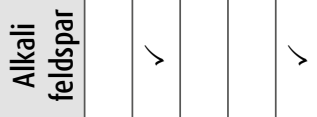

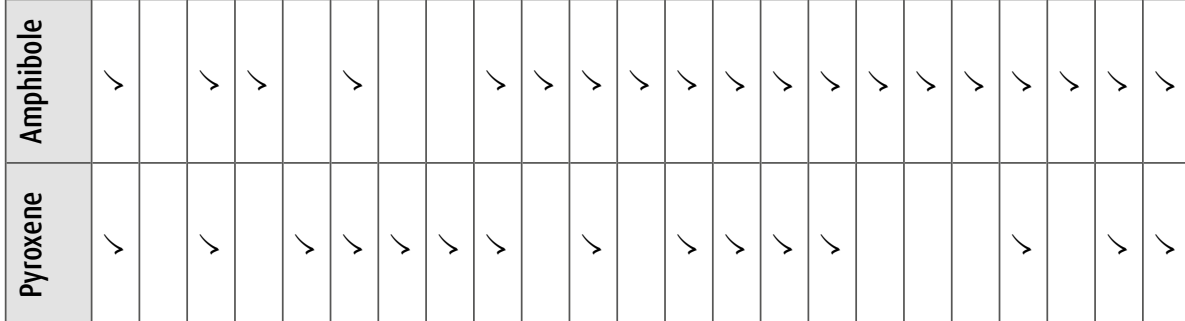

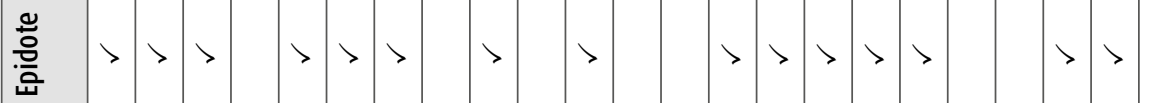

产

总

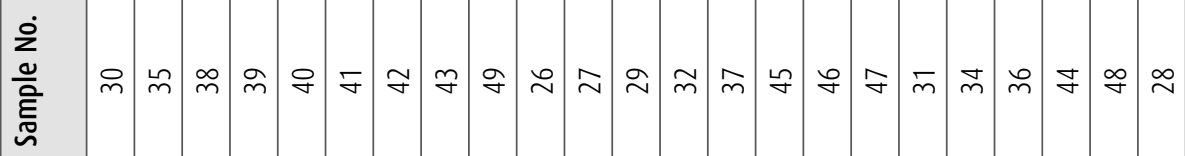

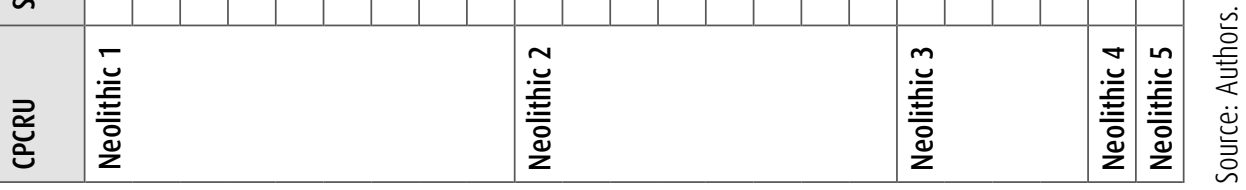


The three prevalent minerals - plagioclase feldspars, quartz and amphibole - along with rarer ones such as zircon, are common in igneous rocks formed through volcanic activity. This geology is typical of the Cagayan Valley as there is a presence of volcanic rock along the Sierra Madre Mountains (Dimalanta and Yumul 2004) and in the plains of the Cagayan River (Mijares 2005). Evidence reveals that the early potters were not using sand as a temper. Instead they were exploiting the alluvial deposits along the banks and flood plains of the Cagayan River that are rich in igneous minerals.

\section{Discussion}

The CPCRUs from the Neolithic and Iron Age clearly separate with the exception of two Neolithic samples (Figures 12.8 and 12.9). Of importance is the apparent reduction of CPCRUs from the Neolithic to the Iron Age, with potters from both periods selecting mineral fillers from the alluvium of the Cagayan Valley sediments. How do we interpret this reduction in pottery clay source selection over time?

If we compare the results to those three models seen in Figures 12.3 to 12.5 we see two correlations. Pottery production from the Neolithic fits more easily with the mobility model (Figure 12.3) with a number of CPCRUs being utilised, each containing a number of separate mineral fillers. As noted in the mobility model, technologically these potters were not conservative, using many combinations of tempers/fillers and different clays to produce similar ware (Figure 12.3). Instead of mobility, another model could involve the importation of pottery from a number of areas, each having a separate CPCRU, although the variability of mineral fillers per CPCRU argues against simple production and exchange models. From a regional perspective it can be seen that many of the Neolithic assemblages from this area are interlinked as seen by excavation and examination of assemblages in the Cagayan Valley. For example, pottery types between Bangag and Catugan share type similarities (Tanaka 2002), as is also the case comparing Pamittan and Magapit in decoration styles (Tanaka and Orogo 2000). The sites dotted along the Cagayan River are not the only areas that share similarities in cultural assemblages. Mijares (2005) found similarities in rim form, surface treatments and petrographic qualities between pottery assemblages from the Cagayan River Valley and the Peñablanca cave sites. In terms of the petrographic analysis, the temper inclusions from the cave sites were derived from the igneous mineral-rich material from the alluvial deposits along the Cagayan River. This in turn matched sherd samples from the Cagayan Valley sites of Nagsabaran, Magapit and Andarayan, as well as a modern sample from Atulu suggesting either interaction between hunter-gatherers from these upland cave sites and the early Austronesian settlers in the open valley (Mijares 2005), or indeed just the wider regional activities of the Austronesian settlers.

The evidence for links between sites throughout the valley shows that there was much interaction between groups, as supported through the chemical analysis undertaken in this research on the variability of clay sources. The early settlers were moving through the land exploiting clay sources for ceramic construction and in addition using fillers from the alluvial plains from along the river. Such movement would foster interaction with other groups resulting in trade and exchange and the cultural transmission of ideas such as pottery styles and techniques.

This differs from the later Iron Age pottery production where two CPCRUs were being utilised for all but one sample. However, the picture is more complicated as there is still a variety of mineral fillers being utilised for the Iron Age pottery. Nevertheless, they are being used with an apparent reduction in clay sources. The fewer number of clay sources could indicate a localisation in pottery manufacturing that would be indicative of a more settled community. Still, neither the Neolithic or Iron Age patterns fits the specialist trader model shown in Figure 12.5. 


\section{Conclusions}

This paper aimed to shed light on the nature of Austronesian societies associated with the spread of the Neolithic through Island Southeast Asia by focusing on the changing nature of settlement through pottery production from the Neolithic to the Iron Age in the Cagayan Valley. The results suggest a change in pottery production from the Neolithic to Iron Age, which is interpreted here as a change in settlement pattern from a mobile/interactive society to a more sedentary one in the Iron Age.

Of interest is the hiatus between the Neolithic and Iron Age period pottery production. There have been major geomorphological events occurring that may partially explain the hiatus. Possible flooding obscuring the cultural transition between the Neolithic and Iron Age has been noted (Tanaka 2002). This relates to mobility in the area and change through time, as a flooding of sites along the Cagayan River would have resulted in the abandonment of these areas. This was witnessed in the stratigraphy of the Nagsabaran site with the absence of cultural material in Spit 10. After 500 years, the site was inhabited again by Iron Age peoples who were characteristically a sedentary group, compared to the Neolithic peoples who earlier inhabited the site. It is unknown who these people were, but the material culture from the Iron Age along the valley does share cultural similarities with Taiwan, especially in terms of the black pottery. This evidence suggests the establishment of continual trading connections and interactions between Taiwan and sedentary Iron Age groups in the Cagayan Valley. Connection and interaction are further supported by the theory of maritime trading networks during the Iron Age (Hung et al. 2007).

Our results agree with other evidence that the early Austronesians were highly mobile people, not only in Southeast Asia but also to the east in Micronesia. It is from ISEA that people may have colonised the Marianas for the first time (Hung et al. 2011). Hung and her colleagues (2012) do not suggest that the Marianas were directly settled from the Cagayan Valley but stress that the pottery style was shared between these two regions. The first settlements in the Marianas occurred at 3500 BP while the first Neolithic settlements in Northern Luzon occurred at 4000 BP (Hung et al. 2011) suggesting that after a period of 500 years a group of Neolithic peoples of the Northern Philippines succeeded in travelling the 2,300 km of open sea to the Marianas.

The Austronesian-speaking peoples expanded rapidly through ISEA, through the Bismarck Archipelago and into the Pacific, punctuated by stops lasting only a few hundred years. The variability of the clay sources found in the early settlement phase at Nagsabaran is consistent with other evidence for the mobile nature of early Austronesian speaking peoples.

\section{Acknowledgements}

The authors would like to thank David Prior and Kat Lilly from the Department of Geology and the Otago Microscopy Department for the use and instruction of the FEGSEM. We wish to thank the National Museum of the Philippines for permission to excavate and loan of the materials. We thank Brent Pooley for his assistance in sample making. 


\section{References}

Amano, N., Piper, P., Hung, H-c., and Bellwood, P. 2013. Introduced domestic animals in the Neolithic and Metal Age of the Philippines: Evidence from Nagsabaran, Northern Luzon. The Journal of Island and Coastal Archaeology 8: 317-335. doi.org/10.1080/15564894.2013.781084.

Anderson, A., S. Bedford, G. Clark, I. Lilley, C. Sand, G.R. Summerhayes and R. Torrence. 2001. An Inventory of Lapita Sites containing dentate-stamped pottery. In G. Clark, A. Anderson and T. Sorovi-Vunidilo (eds), The Archaeology of Lapita Dispersal in Oceania: Papers from the Fourth Lapita Conference, June 2000, pp. 1-14. Terra Australis 17. Canberra: Department of Archaeology and Natural History, and Centre for Archaeology, The Australian National University.

Aoyagi, Y., M.L. Jr. Aguilera, H. Ogawa and K. Tanaka. 1986. The shell midden in the lower reaches of the Cagayan River. The Journal of Sophia Asian Studies 4: 45-91.

Bedford, S. and C. Sand. 2007. Lapita and Western Pacific settlement: Progress, prospects and persistent problems. In S. Bedford, C. Sand and S. Connaughton (eds), Oceanic Explorations: Lapita and Western Pacific Settlement, pp. 1-15. Terra Australis 26. Canberra: Department of Archaeology and Natural History and Centre for Archaeology, The Australian National University.

Bellwood, P. 2011. Holocene population history in the Pacific region as a model for worldwide food producer dispersals. Current Anthropology 52(S4): S363-S378. doi.org/10.1086/658181.

— 2013. Southeast Asian Islands: archaeology. In I. Ness (ed.), The Encyclopedia of Global Human Migration, pp. 1-9. Oxford: Blackwell Publishing.

- 2015. Southeast Asian Islands: archaeology. In P. Bellwood (ed.), The Global Prehistory of Human Migration, pp. 284-292. Chichester: Wiley Blackwell.

Bellwood, P. and E. Dizon. 2005. The Batanes Archaeological Project and the 'Out of Taiwan'. Hypothesis for Austronesian Dispersal. Journal of Austronesian Studies 1(1): 1-32.

Bishop, R. and R. Rands. 1982. Mayan fine paste ceramics: a compositional perspective. In J.A. Sabloff (ed.), Analyses of Fine Paste Ceramics. Excavations at Siebal, pp. 283-314. Cambridge: Harvard University, Memoirs of the Peabody Museum of Archaeology and Ethnology.

Bishop, R., R. Rands and G. Holley. 1982. Ceramic compositional analyses in archaeological perspective. Archaeological Method and Theory 5: 275-320.

Carson, T, H.-c. Hung, G.R. Summerhayes and P. Bellwood. 2013. The pottery trail from Southeast Asia to Remote Oceania. The Journal of Island and Coastal Archaeology 8(1): 17-36. doi.org/10.1080/1556 4894.2012.726941.

Deer, W.A., R.A. Howie and J. Zussman. 1992. An Introduction to The Rock-Forming Minerals. 2nd edition. Hong Kong: Longman Scientific \& Technical.

Diamond, J. 1988. Express train to Polynesia. Nature 336: 307-308. doi.org/10.1038/336307a0.

Dimalanta, C.B. and G.P. Jr. Yumul. 2004. Crustal thickening in an active margin setting (Philippines): The whys and the hows, Episodes 27: 260-264.

Froh, J. 2004. Archeological ceramics studied by Scanning Electron Microscopy. Hyperfine Interactions 154: 159-176. doi.org/10.1023/B:HYPE.0000032074.98045.cc.

Gnauck, P. P. Hoffrogge and J. Greiser. 2002. A New CrossBeam ${ }^{\circ}$ Inspection Tool combining an ultrahigh resolution field emission SEM and a high resolution FIB. Metrology, Inspection, and Process Control for Microlithography vol. 16, no. 833, viewed 27 September 2013, dx.doi.org/10.1117/12.473530. 
Green, R.C. 1991. The Lapita cultural complex: Current evidence and proposed models. Bulletin of the Indo-Pacific Prehistory Association 11: 295-305. doi.org/10.7152/bippa.v11i0.11393.

2000. Lapita and the cultural model for intrusion, integration, and innovation. In A. Anderson and T. Murray (eds), Australian Archaeologist: Collected Papers in Honour of Jim Allen, pp. 372-392. Canberra: Coombs Academic Publishing.

2003. The Lapita horizon and traditions - Signature for one set of oceanic migrations. In C. Sand (ed.), Pacific Archaeology: Assessments and Prospects (Proceeding of the Conference for the 50th Anniversary of the Frst Lapita Excavation. Koné-Nouméa 2002), pp. 95-120. Nouméa: Les Cahiers de larchéologie en Nouvelle-Calédonie 15.

Hogg, N. 2007. Settling Down: Mobility Patterns of Three Mid-Late Lapita Sites in the Anir Group, Papua New Guinea. Unpublished BA (Hons) thesis, University of Otago, Dunedin.

Hung, H.-c. 2005. Neolithic Interaction between Taiwan and Northern Luzon: The pottery and jade evidence from the Cagayan Valley. Journal of Austronesian Studies 1(1): 109-131.

2008. Migration and Cultural Interaction in Southern Coastal China, Taiwan and the Northern Philippines, 3000 BC to AD 100: The Early History of the Austronesian-Speaking Populations. Unpublished PhD thesis, The Australian National University, Canberra.

Hung, H.-c., Y. Iizuka, P. Bellwood, K.D. Nguyen, B. Bellina, P. Silapanth, E. Dizon, R. Santiago, I. Datan and J.H. Manton. 2007. Ancient jades map 3,000 years of prehistoric exchange in Southeast Asia. Proceedings of the National Academy of Sciences 104(50): 19745-19750. doi.org/10.1073/ pnas.0707304104.

Hung, H.-c., M.T. Carson, P. Bellwood, F.Z. Campos, P.J. Piper, E. Dizon, M.J.L.A. Bolunia, M. Oxenham and Z. Chi. 2011. The first settlement of Remote Oceania: The Philippines to the Marianas. Antiquity 85: 909-926. doi.org/10.1017/S0003598X00068393.

Hung, H.-c., M.T. Carson and P. Bellwood. 2012. Earliest settlement in the Marianas - a response. Antiquity 86(333): 910-914. doi.org/10.1017/S0003598X00048006.

Mijares, A.S. 2005. The archaeology of Penablanca Cave sites, Northern Luzon, Philippines. Journal of Austronesian Studies 1(2): 65-92.

Niziolek, L.C. 2013. Earthenware production and distribution in the Prehispanic Philippine polity of Tanjay: Results from laser ablation-inductively coupled plasma-mass spectrometry (LA-ICP-MS). Journal of Archaeological Science 40: 2824-2839. doi.org/10.1016/j.jas.2013.02.020.

Ogawa, H. 2002. Archaeological Research on the Lower Cagayan River: Study on the Historical Process of Hunter-Gather/Farmer Interdependent Relationship, Tokyo: Tokyo University of Foreign Studies.

Summerhayes, G.R. 1997. Losing your temper: The effect of mineral inclusions on pottery analyses. Archaeology in Oceania 32(1): 108-117. doi.org/10.1002/j.1834-4453.1997.tb00376.x.

2000a. Lapita Interaction. Terra Australis 15. Canberra: Department of Archaeology and Natural History and the Centre for Archaeological Research, The Australian National University.

- 2000b. Recent archaeological investigations in the Bismarck Archipelago, Anir-New Ireland Province, Papua New Guinea. Bulletin of the Indo-Pacific Prehistory Association 19(3): 167-174.

- 2003. Modelling differences between obsidian and pottery distribution patterns in the Bismarck Archipelago In C. Sand (ed.), Pacific Archaeology: Assessments and Prospects (Proceeding of the International Conference for the 50th Anniversary of the First Lapita Excavation. Koné-Noumé July 1952), pp. 139-149. Nouméa: Les Cahiers de larchéologie en Nouvelle-Calédonie 15. 
2004. The nature of prehistoric obsidian importation to Anir and the development of a 3,000 year old regional picture of obsidian exchange within the Bismarck Archipelago, Papua New Guinea. In V.J. Attenbrow and R. Fullagar (eds), Archaeologist and Anthropologist in the Western Pacific: Essays in Honour of Jim Specht, pp. 145-156. Sydney: Records of the Australian Museum Supplement 29.

—. 2007. Island Melanesian pasts - a view from archaeology. In J. Friedlaender (ed.), Genes, Languages and Culture History in the Southwest Pacific, pp. 10-35. New York: Oxford University Press.

Swete Kelly, M.C. 2008. Prehistoric Social Interaction and the Evidence of Pottery in the Northern Philippines. Unpublished $\mathrm{PhD}$ thesis, The Australian National University, Canberra.

Tanaka, K. 2002. Ceramic Chronology in Northern Luzon: Typological Analysis of the Pottery from the Lal-lo Shell-middens. Unpublished PhD thesis, University of the Philippines, Manila.

Tanaka, K., and A.B. Orogo. 2000. The archaeological excavation at the Pamittan site, Barangay Lanna, Solana, Cagayan Province, Philippines, Journal of Environmental Studies 8: 113-142.

Wright, R.V.S. 1991. Doing Mulitvariate Archaeology and Prehistory: Handling Large Data Sets with $M V-A R C H$. Department of Anthropology, University of Sydney.

Zhou, W., R.P. Apkarian, Z.L. Wang and D. Joy. 2006. Fundamentals of Scanning Electron Microscopy. In W. Zhou and Z.L. Wang (eds), Scanning Microscopy for Nanotechnology: Techniques and Applications, pp. 1-39. New York: Springer. doi.org/10.1007/978-0-387-39620-0_1. 
This text is taken from New Perspectives in Southeast Asian and Pacific Prehistory, edited by Philip J. Piper, Hirofumi Matsumura and David Bulbeck, published 2017 by ANU Press, The Australian National University, Canberra, Australia. 